\title{
Modelling autocatalytic behaviour of a food model system - Sucrose thermal degradation at high concentrations
}

\author{
M. Quintas, T.R.S. Brandão, C.L.M. Silva * \\ Laboratório de Optimização de Processos Alimentares, Escola Superior de Biotecnologia, Universidade Católica Portuguesa, \\ Rua Dr. António Bernardino de Almeida, 4200-072 Porto, Portugal
}

Keywords: Sucrose thermal degradation; Concentrated solutions; Autocatalytic reactions; Arrhenius and mixed model effects

\begin{abstract}
Sucrose thermal degradation is an important reaction in the food industry. When in concentrated and neutral solutions, pure sucrose presents a lag phase in the reaction. This work aimed at: (i) modelling sucrose thermal degradation autocatalytic behaviour and (ii) studying the concentration and temperature effects on kinetic parameters. Isothermal experiments were conducted at temperatures ranging from 100 to $180{ }^{\circ} \mathrm{C}$, using solutions with varying water content $(3.58-30.03(\% \mathrm{w} / \mathrm{w}))$. The logistic and Gompertz sigmoidal equations were modified and reparameterised, in order to describe degradation behaviour with kinetic parameters with physical meaning (maximum reaction rate, $k_{\max }$, and lag time, $\lambda$ ). In both models these parameters presented an Arrhenius type dependence on temperature. Following a mixed model effect methodology, the concentration dependence was observed on the Arrhenius parameters. This concentration effect was included in the proposed kinetic models, which were able to successfully describe experimental data.
\end{abstract}

\section{Introduction}

Sucrose thermal degradation is an important reaction in the food industry, since it is responsible for either important characteristics of the final food products or can influence the yield of obtainable white sugar in sugar manufacture. This degradation may occur by two different major reaction pathways: the Maillard reaction, which takes place in the presence of amino acids, and caramelisation, that occurs when sucrose is heated at high temperatures (BeMiller \& Whistler, 1996). The Maillard reaction kinetics has been widely studied in the food science field (Baisier \& Labuza, 1992; Buera, Chirifie, Resnik, \& Wetzler, 1987; Imming, Buczys, Lehnberger, \& Bliesener, 1996; van Boekel, 2001). Caramelisation, on the other hand, is considered to follow a simpler reaction pathway

\footnotetext{
* Corresponding author. Tel.: +351 2255800 58; fax: +351 2250903 51. E-mail address: clsilva@esb.ucp.pt (C.L.M. Silva).
}

and consequently fewer studies have been dedicated to its kinetics.

Caramelisation reaction is influenced by $\mathrm{pH}$, impurities (salts) and sucrose concentration of the solution, and several authors approached these aspects (Clarke, Edye, \& Eggleston, 1997; Eggleston \& Vercellotti, 2000; Lowary \& Richards, 1988; Mauch, 1971; Richards, 1986; Vukov, 1965). Most of those works are in a range of low sucrose concentration $(<70 \%(\mathrm{w} / \mathrm{w}))$, relatively low processing temperatures $\left(<85^{\circ} \mathrm{C}\right)$, presence of impurities and/or acidic or alkaline media (Mauch, 1971). A first-order model is often used to describe the heat degradation of sucrose under such conditions (Buera et al., 1987; Vukov, 1965). There is little information on the kinetics of sucrose thermal degradation at high concentrations. Schoebel, Tannenbaum, and Labuza (1969) studied sucrose degradation under these conditions. Still, this research was related to acidic saturated solutions and a first-order reaction was observed.

However, in some cases, like specific confectionery products (Davies \& Labuza, 1997) or sugar boiling during white 


\section{Nomenclature}

$a, b, c$ mathematical parameters in the logistic and Gompertz equations

$C_{1}$ to $C_{7}$ parameters of the global logistic and Gompertz models

$C \quad$ sucrose concentration (w/w (\%))

$C_{0} \quad$ initial sucrose concentration (w/w (\%))

$e \quad$ Napier's constant

$E_{\text {a }} \quad$ activation energy $\left(\mathrm{J} \mathrm{mol}^{-1}\right)$

$E_{\mathrm{a} k_{\max }}$ activation energy for the $k_{\max }$ parameter $\left(\mathrm{J} \mathrm{mol}^{-1}\right)$

$E_{\mathrm{a} \lambda} \quad$ activation energy for the $\lambda$ parameter $\left(\mathrm{J} \mathrm{mol}^{-1}\right)$

$k_{\max }$ maximum reaction rate $\left(\mathrm{min}^{-1}\right)$

$k_{\text {max }_{\text {ref }}}$ maximum reaction rate at reference temperature $\left(\min ^{-1}\right)$

$\lambda \quad$ lag time (min) $\lambda_{\text {ref }} \quad$ lag time at reference temperature (min)

MSE mean square error

$p \quad$ kinetic parameter

$p_{\text {ref }} \quad$ kinetic parameter at finite reference temperature

$P \quad$ probability

$R \quad$ universal gas constant $\left(8.314 \mathrm{~J} \mathrm{~mol}^{-1} \mathrm{~K}^{-1}\right)$

$R^{2} \quad$ coefficient of determination

SE standard error

SHW standardised half with (\%)

$t \quad$ time $(\mathrm{min})$

$T$ temperature $\left({ }^{\circ} \mathrm{C}\right.$ or $\left.\mathrm{K}\right)$

$T_{\text {ref }} \quad$ reference temperature $\left({ }^{\circ} \mathrm{C}\right.$ or $\left.\mathrm{K}\right)$

$W \quad$ water content (w/w (\%))

$x \quad$ independent variable

$y \quad$ dependent variable sugar production (Richards, 1986), high concentrated sucrose solutions are heated at high temperatures, neutral $\mathrm{pH}$ and a lag phase on sucrose degradation occurs (Clarke et al., 1997; Eggleston, Trask-Morrel, \& Vercellotti, 1996; Lowary \& Richards, 1988; Richards, 1986). Eggleston et al. (1996) modelled such behaviour assuming a pseudofirst-order reaction for concentrated sucrose thermal degradation in the presence of different salts. A lag phase was also observed by Eggleston (2002) when studying cane juice stored at factory room temperature, where the sucrose degradation was due to the combined action of microbial, enzymatic and chemical reaction (acidic degradation). Haghighat-Khajavi, Kimura, Oomori, Matsuno, and Adachi (2005) found this type of behaviour in thermal degradation of sucrose in subcritical water (high pressure and high temperature conditions). An induction period was also observed in non-enzymatic browning of freeze dried model systems containing sucrose (Karel \& Labuza, 1968; Labuza, Tannenbaum, \& Karel, 1970).

The lag phase and consequent sinusoidal behaviour observed in pure, high concentrated and neutral solutions treated at high temperatures, suggests an autocatalytic type reaction. This autocatalytic nature is probably due to two main factors: (i) formation of weak acids during the first step of sucrose hydrolysis, that decreases solutions' $\mathrm{pH}$ and thus accelerates the reaction (Kroh, 1994; Lowary \& Richards, 1988; Poncini, 1980) and (ii) molecular mobility. In the last decade, scientists started to realise the importance of molecular mobility, influenced by temperature and amount of water molecules in the system, in typical food reactions (Bell \& Labuza, 1994; Karel, 1993; Kouassi \& Roos, 2001; Slade \& Levine, 1991). In sucrose hydrolysis, water can act as a solvent or reactant (Labuza et al., 1970). In concentrated solutions, there is a decreased molecular mobility in the system as well as a deficit in the available water molecules for the reaction to occur, which may explain the existence of a lag phase. Further- more, studies on sucrose crystals indicate that sucrose degradation products depress the melting point, leading to a type of autocatalysis reaction by the increased molecular mobility (Poncini, 1981). In the amorphous state, the increase of molecular mobility during the reaction may also be explained by lower molecular weights of the degradation products (i.e. fructose and glucose) when compared with sucrose.

This work aims at modelling the reaction of sucrose thermal degradation at concentrated solutions, neutral $\mathrm{pH}$ and absence of impurities, where a lag phase is evident. To achieve that, experiments were carried out with concentrated sucrose solutions of $70-97 \%(\mathrm{w} / \mathrm{w})$, treated at temperatures ranging from 100 to $180^{\circ} \mathrm{C}$ for different times. The kinetic behaviour was mathematically described using the logistic and Gompertz equations, and the temperature and concentration dependence of the kinetic parameters was investigated.

\section{Theoretical considerations}

Modelling autocatalytic behaviour

An entire autocatalytic reaction, with lag and exponential phases, presents a sinusoidal shape resembling the microbial growth/inactivation behaviour. The logistic (Gibson, Bratchel, \& Roberts, 1987; Neter, Knuter, Nachtsheim, \& Wasserman, 1996; Zwietering, Jöngenburger, Rombouts, \& Riet, 1990) and Gompertz (Gibson et al., 1987; Gompertz, 1825; Zwietering et al., 1990) equations are widely used in predictive microbiology studies. The original forms of logistic and Gompertz expressions, which are included in Table 1 (Eqs. (1) and (2)), describe a growth tendency (Fig. 1a; $a$ is the assymptotic value of both functions and $b$ and $c$ are shape parameters). These functions were reparameterised by Zwietering et al. (1990), to parameters with biological meaning for microorganisms growth. 
Table 1

The logistic and Gompertz models reparameterisation for autocatalytic behaviour

\begin{tabular}{|c|c|c|c|}
\hline Function & Original $^{\mathrm{a}}$ & Modified $^{\mathrm{b}}$ & Reparameterised $^{\mathrm{b}}$ \\
\hline \multirow[t]{2}{*}{ Logistic } & $y=\frac{a}{1+\exp (b-c x)}$ & $y=a-\frac{a}{1+\exp (b-c x)}$ & $\frac{C}{C_{0}}=\frac{1}{1+\exp \left[2 k_{\max }(\lambda-t)+1\right]}$ \\
\hline & $x$ as independent variable & $x$ as independent variable & $t$ as independent variable \\
\hline \multirow[t]{2}{*}{ Gompertz } & $y=a \exp [-\exp (b-c x)]$ & $y=a-a \exp [-\exp (b-c x)]$ & $\frac{C}{C_{0}}=1-\exp \left\{-\exp \left[k_{\max } e(\lambda-t)+1\right]\right\}$ \\
\hline & $x$ as independent variable & $x$ as independent variable & $t$ as independent variable \\
\hline
\end{tabular}

a Zwietering et al. (1990).

b This study.

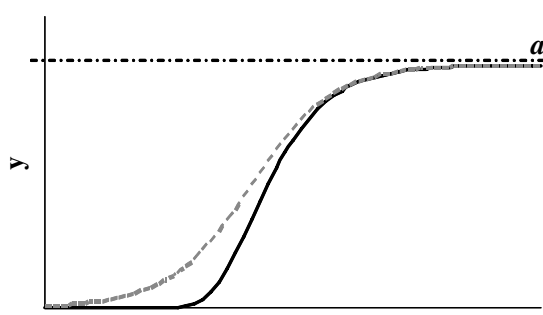

(a)

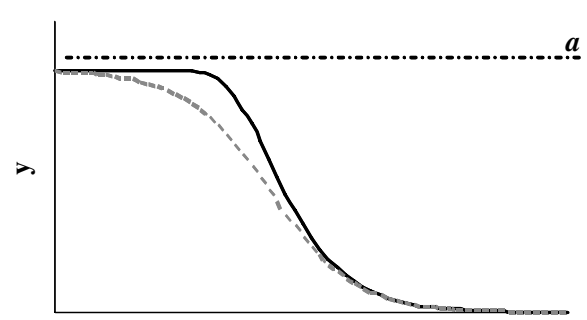

(b)

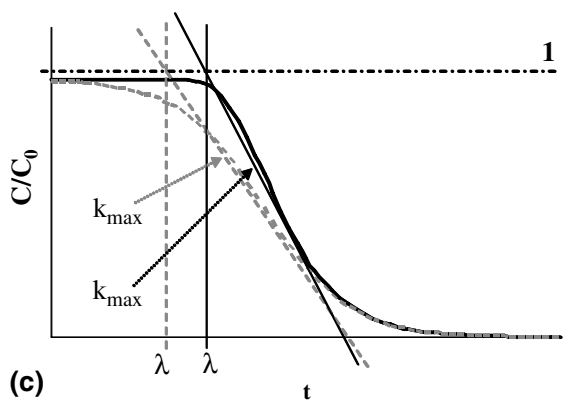

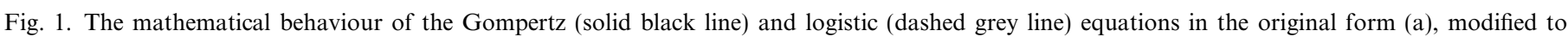
describe inactivation behaviour (b) and reparameterised (c).

For the case of inactivation behaviour/degradation kinetics, the expressions can be modified (see also Table 1, Eqs. (3) and (4), Fig. 1b). For an autocatalytic chemical reaction, more convenient reparameterised mathematical forms can represent the variation of the normalized reactant concentration $C / C_{0}$ with time $(t)$. The parameter $a$ becomes 1 , and a maximum reaction rate, $k_{\max }$ (determined by the slope of the steepest tangent to the exponential phase), and a lag time, $\lambda$ (calculated by the interception of the assymptot with the extrapolated tangent line), can be used (Table 1, Eqs. (5) and (6), Fig. 1c).

\section{Modelling temperature and concentration effects on a degradation reaction}

Temperature is known to have a significant effect on food reactions kinetics. This effect is often translated into a dependence of the kinetic parameters on temperature, which has been widely studied and can be generally expressed with an Arrhenius type equation using a finite reference temperature (Cohen, Birk, Mannheim, \& Saguy, 1994; Haralampu, Saguy, \& Karel, 1985; Peleg, 1992; van Boekel, 1996):

$p=p_{\text {ref }} \exp \left(-\frac{E_{\mathrm{a}}}{R}\left(\frac{1}{T}-\frac{1}{T_{\text {ref }}}\right)\right)$

where $p$ is a kinetic parameter, $E_{\mathrm{a}}$ is activation energy, $p_{\text {ref }}$ the kinetic parameter at finite reference temperature, $T_{\text {ref }}$, and $R$ the universal gas constant. Several studies indicated that if $T_{\text {ref }}$ corresponds to the middle temperature of the experimental range, the correlation between parameters and the confidence intervals will be minimised (Brandão, 2004; Cohen et al., 1994; van Boekel, 1996), thus improving the mathematical modelling quality.

Reactant concentration and water content may also affect reactions kinetics. This effect can be included in the Arrhenius parameters (Eq. (7); $p_{\text {ref }}$ and $E_{\mathrm{a}}$ ), on the basis of experimental data and fitting procedures.

A mixed-model, that includes the influence of one or more main effects and significant interactions, may account empirically for a mathematical description of food reaction kinetics (Saguy \& Karel, 1980).

\section{Materials and methods}

Preparation of the concentrated sucrose solutions

The selected sucrose concentrations were $70 \%, 75 \%$, $83 \%, 87.5 \%$ and $97 \%(\mathrm{w} / \mathrm{w})$.

Sucrose solutions of $70-87.5 \%(\mathrm{w} / \mathrm{w})$ were prepared by weighing commercial sucrose and adding distilled water in the desired proportion. The mixtures were then heated in a microwave oven (medium power) for short periods (1 min), intercalated with agitation until complete sucrose dissolution (Braga da Cruz, MacInnes, Oliveira, \& Malcata, 2002).

To prepare sucrose solutions of $97 \%(\mathrm{w} / \mathrm{w})$, freeze-dried sucrose (commercial) was equilibrated with a saturated salt 
solution of lithium bromide (purum p.a., Fluka), of $\mathrm{aw}_{@ 27^{\circ} \mathrm{C}} 6 \%$, under vacuum, until constant weight.

\section{Water content determination}

A Karl Fisher coulometric determination ( $684 \mathrm{~K}$ coulometer, Metrohm, Switzerland) was used to measure the real moisture content of concentrated sucrose solutions. At least three different batches were prepared for each concentration and each batch was analysed three times. The $95 \%$ standard error (SE) of the sample water content was calculated.

\section{Heat treatment of concentrated sucrose solutions}

The concentrated sucrose solutions were poured into Thermal Death Time (TDT) cans, $6 \mathrm{~cm}$ diameter and $0.8 \mathrm{~cm}$ height $(208 \times 0.06$, American National Can, USA), sealed under vacuum, and processed isothermally at 100 , $120,140,160$ and $180^{\circ} \mathrm{C}$ in an oil bath (polyethylene glycol 400 , Clariant) for different times.

\section{Analytical determination of sucrose content}

After processing, the samples were transferred into a flask and weighed. Water was added and the diluted samples were weighed and frozen for posterior analysis.

Sucrose content of the heat treated solutions was determined using high pressure liquid chromatography. Standard solutions were prepared from sucrose (for biochemistry, Merck). Both samples and standard solutions were injected (AS-15550, Jasco, Japan) in a HPLC system, using a pump (PU-1580, Jasco) with a $\mathrm{NH}_{2}$ (Merck Licrospher ${ }^{\circledR} 100 \mathrm{NH}_{2} 5 \mu \mathrm{m}$ ) column. The mobile phase, acetonitrile (Isocratic Grade, Lichrosolv, Merck)/water (80:20), was running at $1.5 \mathrm{ml} / \mathrm{min}$. The peaks were detected using a Refractive Index detector (RI-1530, Jasco) and analysed using Jasco-Borwin software v.1.50 (JMBS Developments, Fontaine, France).

\section{Statistical procedures}

\section{Experimental design}

Previous analyses were performed in order to evaluate if water content and temperature had a significant effect on sucrose thermal degradation. Experiments were conducted following a $2^{2}$ design (Box, Hunter, \& Hunter, 1978) at two water content levels (30.03 and $3.58(\mathrm{w} / \mathrm{w} \%))$ ) and two temperature levels $\left(120\right.$ and $\left.160{ }^{\circ} \mathrm{C}\right)$. Results were analysed using Experimental Design package of STATISTICA ${ }^{\mathrm{TM}}$ v 6.0 (Statsoft ${ }^{\circledR}$, Tulsa, OK, USA).

\section{Non-linear regression analysis}

The equations mentioned along the text were fitted to data by non-linear regression analysis, using a package of STATISTICA $^{\mathrm{TM}} \vee$ 6.0. The Levenberg-Marquadt algorithm for the least squares function minimisation was used. The statistical indicators of the quality of the regression, coefficient of determination $\left(R^{2}\right)$ and the mean square error (MSE, i.e. the sum of squares of residuals divided by the corresponding degrees of freedom), and the $95 \%$ standard error of the parameters (SE) were obtained directly from the software. The precision of the estimated parameters was also evaluated by the standardised half width (SHW), which was defined as the ratio between the 95\% standard error and the value of the estimate.

\section{Results and discussion}

\section{Water content of the concentrated sucrose solutions}

The water content of the sucrose solutions is presented in Table 2. Since high temperatures are used in samples preparation, some evaporation occurs, which may explain in some cases lower water content values than expected from the "nominal" concentration, i.e. the concentration calculated with the commercial sucrose and water weights used in the solutions preparation.

\section{Factorial design analysis}

A factorial analysis was previously performed in order to test the influence of water content and temperature on the reaction. These effects, if existent, will be translated into an effect on the kinetic parameters of either of the two models (see Table 1) chosen for the analysis.

Table 2

Water content of the prepared concentrated sucrose solutions (nominal concentration), corresponding standard error (SE) at $95 \%$ and sucrose concentration

\begin{tabular}{lll}
\hline $\begin{array}{l}\text { Nominal sucrose } \\
\text { concentration }(\mathrm{w} / \mathrm{w} \%)\end{array}$ & $\begin{array}{l}\text { Water content } \pm 95 \% \\
\text { SE }(\mathrm{w} / \mathrm{w} \%)\end{array}$ & $\begin{array}{l}\text { Sucrose concentration } \\
(\mathrm{w} / \mathrm{w} \%)\end{array}$ \\
\hline 70.00 & $30.03 \pm 0.28$ & 69.97 \\
75.00 & $25.30 \pm 0.63$ & 74.70 \\
83.00 & $16.32 \pm 0.82$ & 83.68 \\
87.50 & $12.20 \pm 0.42$ & 87.80 \\
97.00 & $3.58 \pm 0.50$ & 96.42 \\
\hline
\end{tabular}

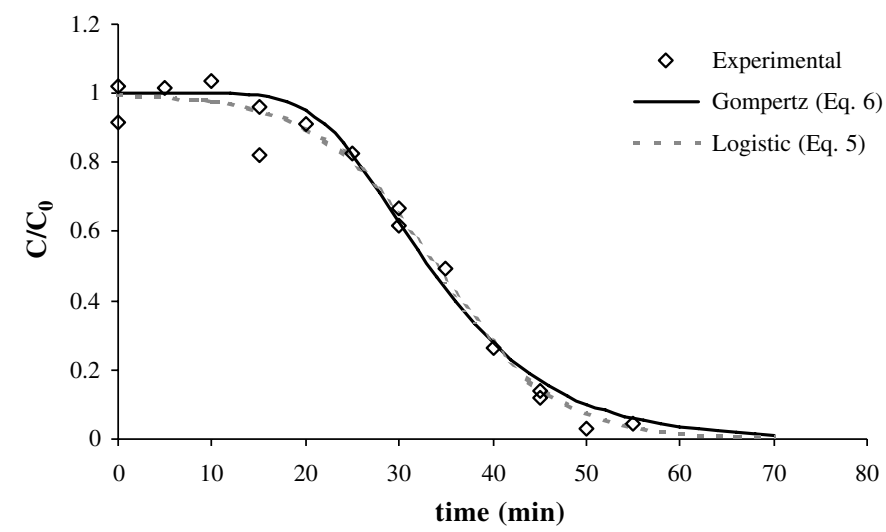

Fig. 2. Results from fitting the logistic (Eq. (5)) and Gompertz (Eq. (6)) models to the experimental data. Example is for a $25.30(\mathrm{w} / \mathrm{w} \%)$ water content sucrose solution processed at $140{ }^{\circ} \mathrm{C}$. 
The logistic function (Eq. 5) was then fitted to experimental data of sucrose thermal degradation and $k_{\max }$ and $\lambda$ parameters were estimated.

The analysis of variance (ANOVA) showed that $\lambda$ and $k_{\max }$ estimates were significantly affected by temperature and water content $(P<0.05)$. Regarding the combined effect, $\lambda$ was also affected at $5 \%$ significance level, whereas $k_{\max }$ was only significantly affected at an $8 \%$ level.

These results clearly demonstrate that sucrose thermal degradation is influenced by temperature and water content of the solutions. In face of that, a study with the objective of modelling these effects on the reaction was conducted, in a wider temperature and water content range.

Table 3

Results from fitting the logistic and Gompertz models to experimental data. Estimates of the parameters, $95 \%$ SE and SHW. Indicators of the quality of the regression, $R^{2}$ and MSE

\begin{tabular}{|c|c|c|c|c|c|c|c|c|}
\hline Model & $W(\% \mathrm{w} / \mathrm{w})$ & $T\left({ }^{\circ} \mathrm{C}\right)$ & MSE & $R^{2}$ & $k_{\max }\left(\min ^{-1}\right)$ & SHW (\%) & $\lambda(\min )$ & SHW (\%) \\
\hline \multirow[t]{22}{*}{ Logistic (Eq. (5)) } & \multirow[t]{4}{*}{30.03} & 100 & $1.95 \times 10^{-2}$ & 0.881 & $2.43 \times 10^{-3} \pm 9.88 \times 10^{-4}$ & 40.58 & $431.20 \pm 124.94$ & 28.97 \\
\hline & & 120 & $4.30 \times 10^{-3}$ & 0.967 & $1.29 \times 10^{-2} \pm 2.44 \times 10^{-3}$ & 18.90 & $100.47 \pm 10.80$ & 10.75 \\
\hline & & 140 & $7.04 \times 10^{-3}$ & 0.953 & $7.57 \times 10^{-2} \pm 2.15 \times 10^{-2}$ & 28.42 & $21.89 \pm 2.78$ & 12.68 \\
\hline & & 160 & $2.91 \times 10^{-2}$ & 0.776 & $1.79 \times 10^{-1} \pm 8.63 \times 10^{-2}$ & 48.35 & $6.14 \pm 1.79$ & 29.13 \\
\hline & \multirow[t]{4}{*}{25.30} & 100 & $9.65 \times 10^{-3}$ & 0.918 & $1.73 \times 10^{-3} \pm 5.66 \times 10^{-4}$ & 32.68 & $563.68 \pm 127.36$ & 22.59 \\
\hline & & 120 & $1.13 \times 10^{-2}$ & 0.933 & $1.86 \times 10^{-2} \pm 8.75 \times 10^{-3}$ & 47.03 & $121.70 \pm 19.24$ & 15.81 \\
\hline & & 140 & $4.29 \times 10^{-3}$ & 0.973 & $7.84 \times 10^{-2} \pm 1.83 \times 10^{-2}$ & 23.28 & $27.52 \pm 2.20$ & 8.00 \\
\hline & & 160 & $2.57 \times 10^{-2}$ & 0.773 & $2.41 \times 10^{-1} \pm 1.13 \times 10^{-1}$ & 46.91 & $7.24 \pm 1.42$ & 19.63 \\
\hline & \multirow[t]{4}{*}{16.32} & 100 & $1.72 \times 10^{-2}$ & 0.913 & $1.51 \times 10^{-3} \pm 8.72 \times 10^{-4}$ & 57.89 & $1343.32 \pm 248.31$ & 18.48 \\
\hline & & 120 & $9.09 \times 10^{-3}$ & 0.934 & $1.39 \times 10^{-2} \pm 6.64 \times 10^{-3}$ & 47.88 & $186.74 \pm 23.58$ & 12.63 \\
\hline & & 140 & $1.96 \times 10^{-2}$ & 0.854 & $5.45 \times 10^{-2} \pm 3.31 \times 10^{-2}$ & 60.67 & $33.01 \pm 7.65$ & 23.17 \\
\hline & & 160 & $1.95 \times 10^{-3}$ & 0.988 & $2.88 \times 10^{-1} \pm 6.58 \times 10^{-2}$ & 22.82 & $9.63 \pm 0.53$ & 5.46 \\
\hline & \multirow[t]{5}{*}{12.20} & 100 & $7.92 \times 10^{-3}$ & 0.945 & $7.70 \times 10^{-4} \pm 2.29 \times 10^{-4}$ & 29.69 & $985.29 \pm 259.19$ & 26.31 \\
\hline & & 120 & $4.36 \times 10^{-3}$ & 0.972 & $5.47 \times 10^{-3} \pm 1.33 \times 10^{-3}$ & 24.31 & $203.64 \pm 30.59$ & 15.02 \\
\hline & & 140 & $1.62 \times 10^{-2}$ & 0.844 & $1.72 \times 10^{-2} \pm 6.02 \times 10^{-3}$ & 34.92 & $35.98 \pm 14.50$ & 40.30 \\
\hline & & 160 & $2.05 \times 10^{-2}$ & 0.909 & $1.67 \times 10^{-1} \pm 1.21 \times 10^{-1}$ & 72.59 & $14.73 \pm 3.49$ & 23.70 \\
\hline & & 180 & $3.29 \times 10^{-2}$ & 0.811 & $2.48 \times 10^{-1} \pm 1.72 \times 10^{-1}$ & 69.55 & $4.12 \pm 2.02$ & 48.92 \\
\hline & \multirow[t]{5}{*}{3.58} & 100 & $5.30 \times 10^{-2}$ & 0.703 & $2.47 \times 10^{-4} \pm 1.02 \times 10^{-4}$ & 41.20 & $3645.19 \pm 1164.62$ & 31.95 \\
\hline & & 120 & $7.57 \times 10^{-3}$ & 0.952 & $2.38 \times 10^{-3} \pm 4.85 \times 10^{-4}$ & 20.40 & $318.73 \pm 60.82$ & 19.08 \\
\hline & & 140 & $4.54 \times 10^{-2}$ & 0.807 & $1.97 \times 10^{-2} \pm 1.22 \times 10^{-2}$ & 62.00 & $101.62 \pm 20.91$ & 20.58 \\
\hline & & 160 & $2.54 \times 10^{-2}$ & 0.852 & $4.65 \times 10^{-2} \pm 2.13 \times 10^{-2}$ & 45.76 & $23.50 \pm 7.30$ & 31.08 \\
\hline & & 180 & $2.19 \times 10^{-2}$ & 0.875 & $2.36 \times 10^{-1} \pm 1.37 \times 10^{-1}$ & 57.90 & $5.10 \pm 1.83$ & 35.92 \\
\hline \multirow[t]{22}{*}{ Gompertz (Eq. (1)) } & \multirow[t]{4}{*}{30.03} & 100 & $1.84 \times 10^{-2}$ & 0.888 & $1.28 \times 10^{-3} \pm 4.91 \times 10^{-4}$ & 38.35 & $218.49 \pm 163.86$ & 75.00 \\
\hline & & 120 & $4.97 \times 10^{-3}$ & 0.962 & $6.38 \times 10^{-3} \pm 1.27 \times 10^{-3}$ & 19.95 & $55.18 \pm 16.64$ & 30.16 \\
\hline & & 140 & $6.81 \times 10^{-3}$ & 0.955 & $3.80 \times 10^{-2} \pm 1.05 \times 10^{-2}$ & 27.70 & $14.40 \pm 3.89$ & 27.03 \\
\hline & & 160 & $2.97 \times 10^{-2}$ & 0.771 & $8.97 \times 10^{-2} \pm 4.39 \times 10^{-2}$ & 48.94 & $3.01 \pm 2.60$ & 86.37 \\
\hline & \multirow[t]{4}{*}{25.30} & 100 & $1.47 \times 10^{-2}$ & 0.875 & $8.26 \times 10^{-4} \pm 3.33 \times 10^{-4}$ & 40.31 & $206.88 \pm 238.51$ & 115.29 \\
\hline & & 120 & $9.69 \times 10^{-3}$ & 0.943 & $9.41 \times 10^{-3} \pm 4.10 \times 10^{-3}$ & 43.54 & $91.68 \pm 25.17$ & 27.45 \\
\hline & & 140 & $5.32 \times 10^{-3}$ & 0.966 & $4.08 \times 10^{-2} \pm 1.09 \times 10^{-2}$ & 26.62 & $20.91 \pm 3.52$ & 16.82 \\
\hline & & 160 & $3.07 \times 10^{-2}$ & 0.729 & $1.55 \times 10^{-1} \pm 8.57 \times 10^{-2}$ & 55.43 & $6.05 \pm 1.90$ & 31.45 \\
\hline & \multirow[t]{4}{*}{16.32} & 100 & $1.64 \times 10^{-2}$ & 0.917 & $7.14 \times 10^{-4} \pm 3.84 \times 10^{-4}$ & 53.79 & $916.00 \pm 369.35$ & 40.32 \\
\hline & & 120 & $7.41 \times 10^{-3}$ & 0.946 & $6.28 \times 10^{-3} \pm 2.75 \times 10^{-3}$ & 43.85 & $138.34 \pm 34.22$ & 24.73 \\
\hline & & 140 & $2.08 \times 10^{-2}$ & 0.845 & $2.98 \times 10^{-2} \pm 1.87 \times 10^{-2}$ & 62.84 & $24.47 \pm 10.76$ & 43.97 \\
\hline & & 160 & $2.40 \times 10^{-3}$ & 0.985 & $1.36 \times 10^{-1} \pm 3.01 \times 10^{-2}$ & 22.23 & $7.46 \pm 0.83$ & 11.08 \\
\hline & \multirow[t]{5}{*}{12.20} & 100 & $6.68 \times 10^{-3}$ & 0.953 & $3.93 \times 10^{-4} \pm 1.03 \times 10^{-4}$ & 26.29 & $274.91 \pm 339.90$ & 123.64 \\
\hline & & 120 & $2.23 \times 10^{-3}$ & 0.986 & $2.69 \times 10^{-3} \pm 4.53 \times 10^{-4}$ & 16.80 & $96.76 \pm 31.29$ & 32.34 \\
\hline & & 140 & $1.65 \times 10^{-2}$ & 0.841 & $8.90 \times 10^{-3} \pm 2.97 \times 10^{-3}$ & 33.41 & $5.47 \pm 19.92$ & 364.14 \\
\hline & & 160 & $1.79 \times 10^{-2}$ & 0.920 & $8.49 \times 10^{-2} \pm 5.49 \times 10^{-2}$ & 64.67 & $11.27 \pm 4.42$ & 39.22 \\
\hline & & 180 & $3.22 \times 10^{-2}$ & 0.815 & $1.20 \times 10^{-1} \pm 8.03 \times 10^{-2}$ & 66.76 & $1.63 \pm 2.95$ & 181.55 \\
\hline & \multirow[t]{5}{*}{3.58} & 100 & $4.88 \times 10^{-2}$ & 0.727 & $1.23 \times 10^{-4} \pm 4.62 \times 10^{-5}$ & 37.63 & $1299.80 \pm 1540.52$ & 118.52 \\
\hline & & 120 & $6.63 \times 10^{-3}$ & 0.958 & $1.16 \times 10^{-3} \pm 2.11 \times 10^{-4}$ & 18.11 & $63.45 \pm 70.47$ & 111.06 \\
\hline & & 140 & $4.51 \times 10^{-2}$ & 0.808 & $8.59 \times 10^{-3} \pm 4.97 \times 10^{-3}$ & 57.88 & $64.61 \pm 32.55$ & 50.37 \\
\hline & & 160 & $2.28 \times 10^{-2}$ & 0.868 & $2.35 \times 10^{-2} \pm 9.88 \mathrm{E} \times 10^{-3}$ & 42.06 & $10.78 \pm 9.69$ & 89.84 \\
\hline & & 180 & $2.02 \times 10^{-2}$ & 0.885 & $1.15 \times 10^{-1} \pm 6.04 \times 10^{-2}$ & 52.53 & $2.56 \pm 2.49$ & 97.53 \\
\hline
\end{tabular}


Kinetic behaviour of thermal degradation of sucrose in concentrated solutions

A typical behaviour of sucrose thermal degradation data can be observed in Fig. 2 and the results from fitting the logistic and Gompertz equations are presented in Table 3. It can be observed that both models present a similar quality of the regression, assessed by satisfactory $R^{2}$ values (varying between 0.703 and 0.988 ) and identical MSE. However, the precision of $\lambda$ estimates, evaluated on the basis of SHW, is clearly better for the logistic model in all studied conditions. Moreover, a decrease on the precision of the Gompertz $\lambda$ parameter is observed as water content decreases. This may be explained by the fact that highly sucrose concentrated samples are more difficult to handle and thus might be subjected to higher experimental errors. Regarding $k_{\max }$ precision, considerable differences were not observed, either between the two models or between the high and low water content regimes.

It is interesting to note that the estimates of $k_{\max }$ from the logistic function (Eq. (5)) are consistently higher than $k_{\max }$ estimates from Gompertz model (Eq. (6)), which may be justified by the different function shapes (Fig. 1). An identical observation was found for the $\lambda$ parameter. In the logistic function, the lag corresponds to the time necessary to consume $26.9 \%$ of the initial sucrose content, while in the Gompertz model it corresponds to $6.6 \%$.

Overall it can be concluded that both models describe the data satisfactorily, as it can be observed by the example in Fig. 2.

\section{Efect of temperature and water content on the kinetic parameters}

In order to ascertain the temperature effect on the reaction kinetics an Arrhenius type dependence of $k_{\max }$ and $\lambda$ (in Eq. (7) the $p$ parameter becomes $k_{\max }$ or $\lambda$ ) was assumed. The final logistic and Gompertz models thus obtained (Eqs. (8) and (9)):

$\frac{C}{C_{0}}=\frac{1}{1+\exp \left\{2 k_{\text {max }_{\text {ref }}} \exp \left[\frac{-E_{a_{\text {anax }}}}{R}\left(\frac{1}{T}-\frac{1}{T_{\text {ref }}}\right)\left[\lambda_{\text {ref }} \exp \left[\frac{E_{a n}}{R}\left(\frac{1}{T}-\frac{1}{T_{\text {ref }}}\right)\right]-t\right]\right]+1\right\}}$

$$
\begin{aligned}
\frac{C}{C_{0}}= & 1-\exp \left\{-\exp \left[e k_{\text {max }_{\text {ref }}} \exp \left[\frac{-E_{\text {a } k_{\max }}}{R}\left(\frac{1}{T}-\frac{1}{T_{\text {ref }}}\right)\right]\right.\right. \\
& \left.\left.\times\left[\lambda_{\text {ref }} \exp \left[\frac{E_{\mathrm{a} \lambda}}{R}\left(\frac{1}{T}-\frac{1}{T_{\text {ref }}}\right)\right]-t\right]+1\right]\right\}
\end{aligned}
$$

were fitted to the experimental data at all temperatures (Arabshahi \& Lund, 1985; Cohen \& Saguy, 1985; Haralampu et al., 1985; Lund, 1983), at constant water content.

Results of the regressions can be seen in Table 4. The indicators of the quality of the regression, $R^{2}$ and MSE, indicated a good regression procedure in all cases. Estimates precision is similar in both models. The behaviour of $k_{\max }$ and $\lambda$, as a function of temperature, can also be observed in Fig. 3.

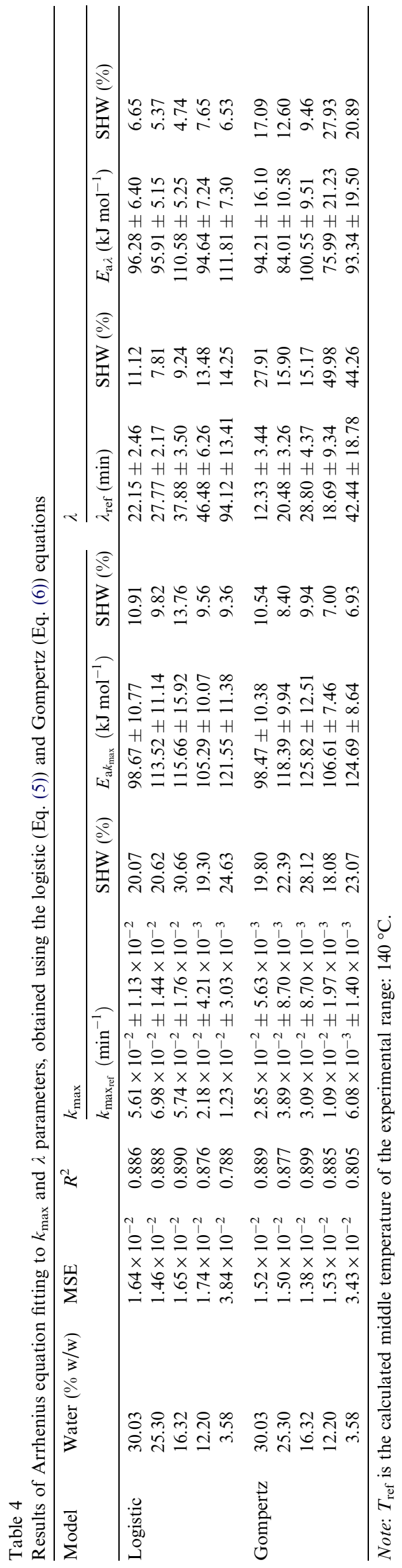




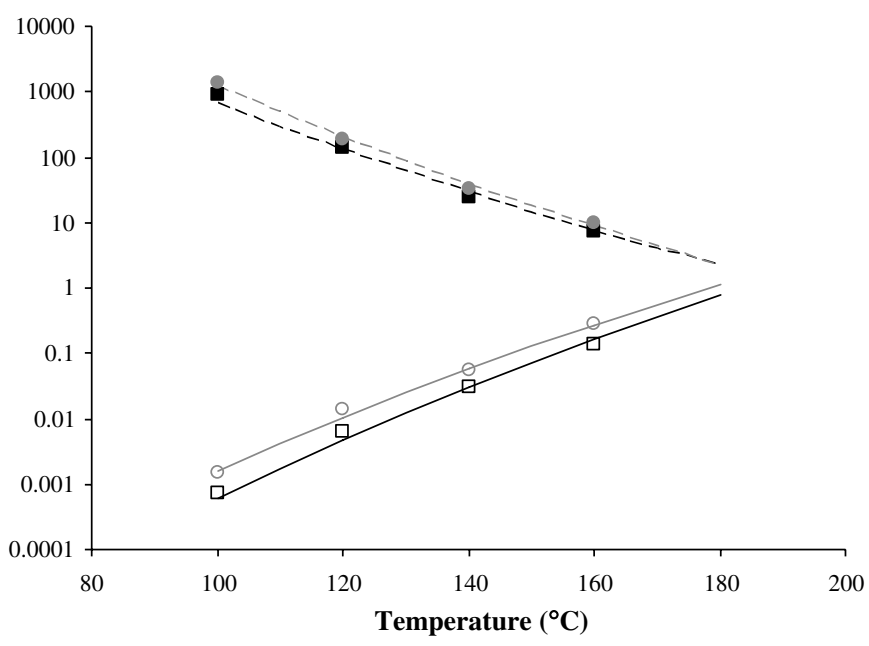

Fig. 3. Comparison of $k_{\max }$ (open symbols) and $\lambda$ (filled symbols) estimated using: (i) the logistic function (Eq. (5)) (grey circles) and (ii) the Gompertz model (Eq. (6)) (black squares) with Arrhenius one-step prediction of $k_{\max }$ (solid lines) and $\lambda$ (dashed lines) using Eqs. (8) (grey lines) and (9) (black lines). Example corresponds to experimental results using $16.32(\mathrm{w} / \mathrm{w} \%)$ water content sucrose solution.

In order to study the water content effect on the reaction, as a first approach, the estimated kinetic parameters (Table 4) were plotted against concentration (Fig. 4). No significant water content effect was observed for the activation energy, for both $k_{\max }$ and $\lambda$ (Fig. $4 \mathrm{~b}$ and d). A similar result was observed for inactivation kinetics of freeze dried $\alpha$-amylase (Saraiva, Oliveira, Hendrickx, Oliveira, \&
Tobback, 1996). However, several other works found a moisture content (or water activity) effect on $E_{\mathrm{a}}$. Nevertheless, most of those studies do not refer the precision of the estimates (e.g. confidence intervals) (Erenturk, Gulaboglu, \& Gultekin, 2005; Kaymak-Ertekin \& Gedik, 2005; Labuza, 1980; Pedreschi, Moyano, Kaack, \& Granby, 2005) and consequently, inference about their significance is impaired. When the precision of the estimates was presented and the water activity effect on $E_{\text {a }}$ was significant, it was only meaningful in extreme limits of an overall range (Manan, Baines, Stone, \& Ryley, 1995; Rapusas \& Driscoll, 1995). The pre-exponential factor of $k_{\max }, k_{\text {max }_{\text {ref }}}$ (Eqs. (8) and (9)), varies linearly with water content (Fig. 4a). Concerning $\lambda_{\text {ref }}$, water content has a linear effect on the Gompertz parameter and an exponential relation was found for the logistic one. These effects can be summarised as:

$$
\begin{aligned}
& E_{\mathrm{a} k_{\max }(\text { logistic or Gompertz })}=C_{1} \\
& E_{\mathrm{a} \lambda(\text { logistic or Gompertz })}=C_{2} \\
& k_{\max _{\mathrm{ref}}(\text { logistic or Gompertz })}=C_{3} W \\
& \lambda_{\text {ref }(\text { logistic })}=C_{4} \exp \left(C_{5} W\right) \\
& \lambda_{\text {ref }(\text { Gompertz })}=C_{6}+C_{7} W
\end{aligned}
$$

where $C_{1}$ to $C_{7}$ are constants and $W$ represents the water content $(\%(\mathrm{w} / \mathrm{w}))$.

These relations (Eqs. (10)-(14)) were embedded in the two models (Eqs. (8) and (9)) to globally describe the
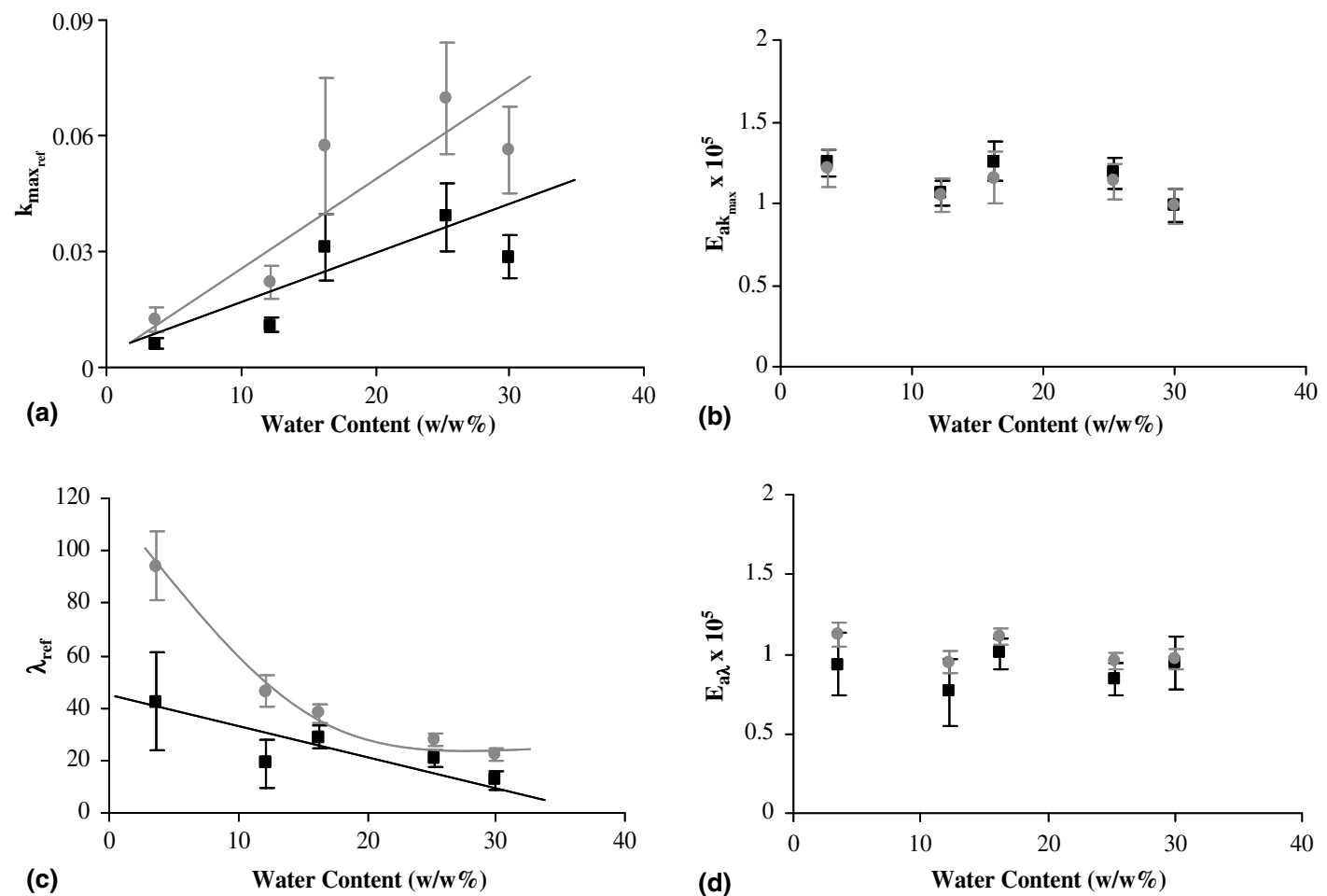

Fig. 4. Effect of concentration on the parameters from logistic (Eq. (8), grey circles) and Gompertz (Eq. (9), black squares) equations. The bars indicate the $95 \%$ confidence limit of each parameter. 
Table 5

Results of global logistic and Gompertz models fitting to experimental data. Evaluation of the quality of the regression on the basis of MSE, $R^{2}$ and residuals randomness and normality. Estimates precision is evaluated using the $95 \% \mathrm{SE}$ and $\mathrm{SHW} \%$

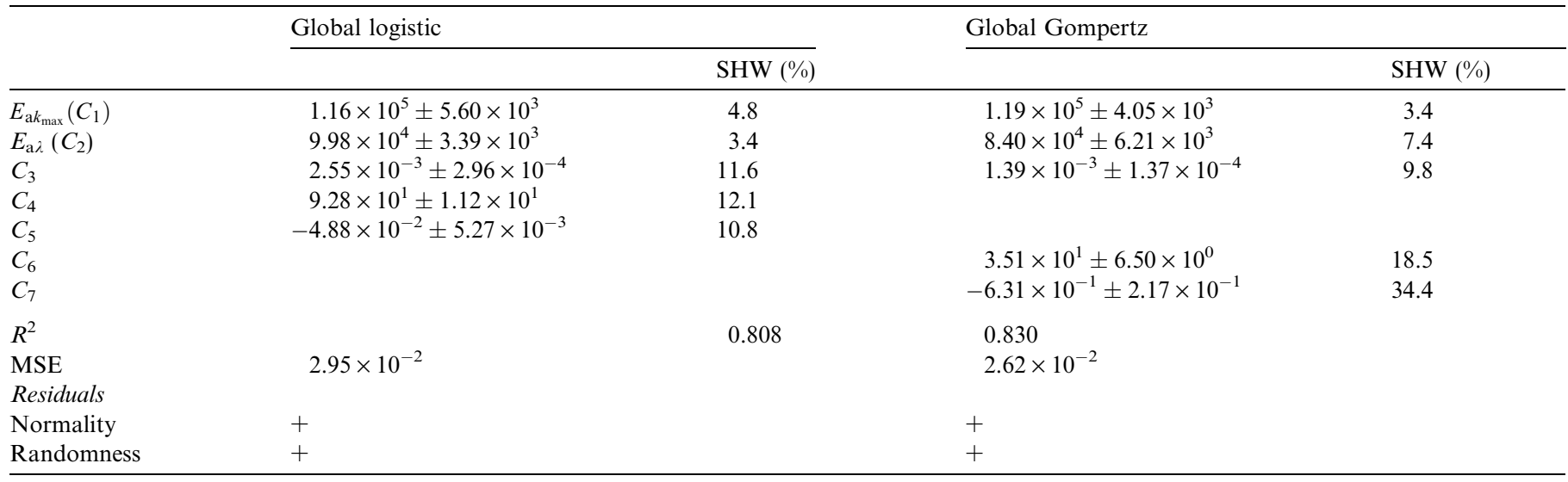

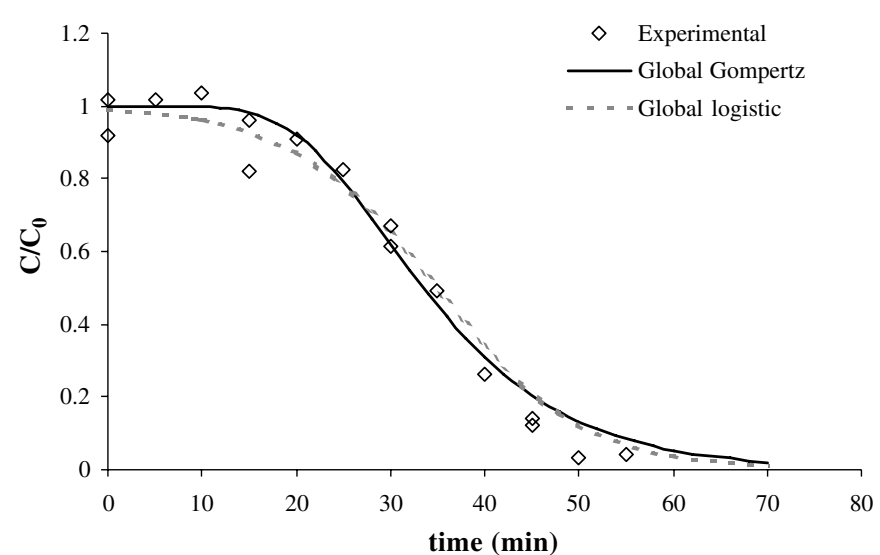

Fig. 5. Global fit of logistic and Gompertz models to the experimental data. Example is for a $25.30(\mathrm{w} / \mathrm{w} \%)$ water content solution processed at $140^{\circ} \mathrm{C}$.

temperature and water content dependence of sucrose thermal degradation.

The results from global fit of logistic and Gompertz models to experimental data are presented in Table 5. Once again it was assessed the adequacy of both models (Fig. 5) and the parameters were estimated with acceptable precision.

Furthermore, the observed concentration and temperature dependence of $k_{\max }$ and $\lambda$ kinetic parameters reinforces the idea of the importance of molecular mobility in sucrose thermal degradation reaction. It was also observed a decrease in solutions $\mathrm{pH}$ (results not shown) along processing time, which could also be responsible for the autocatalytic behaviour of the reaction.

\section{Conclusions}

Results of isothermal kinetic experiments conducted on concentrated neutral solutions of pure sucrose, at temperatures ranging from 100 to $180^{\circ} \mathrm{C}$ and using solutions with varying water content $(3.58-30.03(\% \mathrm{w} / \mathrm{w}))$, showed a lag phase, which was previously described in literature. The logistic and Gompertz equations were modified and reparameterised in order to describe reactions behaviour with kinetic parameters with physical meaning $\left(k_{\max }\right.$ and $\lambda$ ). These models were able to successfully describe reaction's autocatalytic behaviour. The lag phase and reactions rate, described by $\lambda$ and $k_{\max }$, respectively, were dependent on both temperature and water content. The parameters dependence on temperature was described by Arrhenius type equations. The water content dependence was observed on the Arrhenius parameters. Global logistic and Gompertz models were proposed, which were able to successfully describe experimental data in the studied temperature and concentration intervals. These observations reinforce the idea of the importance of molecular mobility in sucrose thermal degradation reaction.

\section{Acknowledgements}

The present work was supported by project POCTI/ EQU/49194/02 "Development of a computational tool to predict the composition of new "sugar free" sweet formulations for traditional Portuguese pastry industrySWEETCOM" supported by FCT, Fundação para a Ciência e a Tecnologia. Author M. Quintas would like to thank Praxis XXI Ph.D. grant BD/20057/99 to FCT.

\section{References}

Arabshahi, A., \& Lund, D. (1985). Considerations in calculating kinetic parameters from experimental data. Journal of Food Process and Engineering, 7(4), 239-251.

Baisier, W. M., \& Labuza, T. P. (1992). Maillard browning kinetics in a liquid model system. Journal of Agriculture and Food Chemistry, 40(5), 707-713.

Bell, L. N., \& Labuza, T. P. (1994). Influence of the low-moisture state on $\mathrm{pH}$ and its implication for reaction kinetics. Journal of Food Engineering, 22(1-4), 291-312.

BeMiller, J. N., \& Whistler, R. L. (1996). Carbohydrates. In O. R. Fennema (Ed.), Food chemistry (3rd ed., pp. 157-224). New York: Marcel Dekker, Inc. 
Box, G. E. P., Hunter, W. G., \& Hunter, J. S. (1978). Statistics for experimenters-An introduction to design, data analysis, and model building (1st ed.). New York: John Wiley and Sons, Inc., pp. 306-344.

Braga da Cruz, I., MacInnes, W. M., Oliveira, J. C., \& Malcata, F. X. (2002). Supplemented state diagram for sucrose from dynamic mechanical thermal analysis. In H. Levine (Ed.), Amorphous food and pharmaceutical systems (1st ed., pp. 59-70). Cambridge: The Royal Society of Chemistry.

Brandão, T. R. S. (2004). Application of non-isothermal methods to the estimation of mass transfer parameters: analysis of the effect of experimental design and data analysis on the precision and accuracy of the estimates-Appendixes. Ph.D. Thesis (pp. D.1-D.16) College of Biotechnology, Porto, Catholic University of Portugal.

Buera, M. P., Chirifie, J., Resnik, S. L., \& Wetzler, G. (1987). Nonenzymatic browning in liquid model systems of high water activity: kinetics of color changes due to Maillard's reaction between different single sugars and glycine and comparison with caramelization browning. Journal of Food Science, 52(4), 1063-1066.

Clarke, M. A., Edye, L. A., \& Eggleston, G. (1997). Sucrose decomposition in aqueous solution and losses in sugar manufacture and refining. Advances in Carbohydrate Chemistry and Biochemistry, 52, 441-470.

Cohen, E., Birk, Y., Mannheim, C. H., \& Saguy, I. S. (1994). Kinetic parameter-estimation for quality change during continuous thermalprocessing of grapefruit juice. Journal of Food Science, 59(1), 155-158.

Cohen, E., \& Saguy, I. (1985). Statistical evaluation of Arrhenius model and its applicability in prediction of food quality losses. Journal of Food Processing and Preservation, 9(4), 273-290.

Davies, C., \& Labuza, T. (1997). Maillard browning of confectioneries. In G. Ziegler (Ed.), Confectionery science (1st ed., pp. 35-66). Happy Valley, PA: Penn State Press.

Eggleston, G. (2002). Deterioration of cane juice-Sources and indicators. Food Chemistry, 78(1), 95-103.

Eggleston, G., Trask-Morrel, B., \& Vercellotti, J. R. (1996). Use of differential scanning calorimetry and thermogravimetric analysis to characterize the thermal degradation of crystalline sucrose and dried sucrose-salt residues. Journal of Agriculture and Food Chemistry, 44(10), 3319-3325.

Eggleston, G., \& Vercellotti, J. R. (2000). Degradation of sucrose, glucose and fructose in concentrated aqueous solutions under constant $\mathrm{pH}$ conditions at elevated temperature. Journal of Carbohydrate Chemistry, 19(9), 1305-1318.

Erenturk, S., Gulaboglu, M. S., \& Gultekin, S. (2005). The effects of cutting and drying medium on the vitamin $\mathrm{C}$ content of rosehip during drying. Journal of Food Engineering, 68(4), 513-518.

Gibson, A. M., Bratchel, N., \& Roberts, T. A. (1987). The effect of sodium chloride and temperature on the rate and extent of growth of clostridium botulinum type A in pasteurized pork slurry. Journal of Applied Bacteriology, 62, 479-490.

Gompertz, B. (1825). On the Nature of the function expressive of the law of human mortality, and on a new mode of determining the value of life contingencies. Philosophical Transactions of the Royal Society of London, 115, 513-585.

Haghighat-Khajavi, S., Kimura, Y., Oomori, T., Matsuno, R., \& Adachi, S. (2005). Kinetics on sucrose decomposition in subcritical water. LWT-Food Science and Technology, 38(3), 297-302.

Haralampu, S. G., Saguy, I. S., \& Karel, M. (1985). Estimation of Arrhenius model parameters using three least squares methods. Journal of Food Processing and Preservation, 9(3), 129-143.

Imming, R., Buczys, R., Lehnberger, A., \& Bliesener, K. M. (1996). A new approach to the kinetics of colour formation in concentrated carbohydrate solutions. Starch/Starke, 48(5), 163-166.

Karel, M. (1993). Temperature-dependence of food deterioration processes. Journal of Food Science, 58(6), ii.
Karel, M., \& Labuza, T. P. (1968). Nonenzymatic browning in model systems containing sucrose. Journal of Agriculture and Food Chemistry, 16(5), 717-719.

Kaymak-Ertekin, F., \& Gedik, A. (2005). Kinetic modelling of quality deterioration in onions during drying and storage. Journal of Food Engineering, 68(4), 443-453.

Kouassi, K., \& Roos, Y. H. (2001). Glass transition and water effects on sucrose inversion in noncrystalline carbohydrate food systems. Food Research International, 34(10), 895-901.

Kroh, L. W. (1994). Caramelisation in food and beverages. Food Chemistry, 51(4), 373-379.

Labuza, T. P. (1980). Enthalpy/entropy compensation in food reactions. Food Technology, 34(2), 67-77.

Labuza, T. P., Tannenbaum, S. R., \& Karel, M. (1970). Water content and stability of low moisture and intermediate-moisture foods. Food Technology, 24(5), 543-548.

Lowary, T. L., \& Richards, G. N. (1988). Effects of impurities on hydrolysis of sucrose in concentrated aqueous solutions. International Sugar Journal, 90(1077), 164-167.

Lund, D. B. (1983). Considerations in modeling food processes. Food Technology, 37(1), 92-94.

Manan, F., Baines, A., Stone, J., \& Ryley, J. (1995). The kinetics of the loss of all-trans retinol at low and intermediate water activity in air in the dark. Food Chemistry, 52(3), 267-273.

Mauch, W. (1971). Chemical properties of sucrose. Sugar Technology Reviews, 1, 239-290.

Neter, J., Knuter, M. H., Nachtsheim, C. J., \& Wasserman, W. (1996). Applied linear statistical models (4th ed.). Chicago: Irwin, pp. 567-573.

Pedreschi, F., Moyano, P., Kaack, K., \& Granby, K. (2005). Color changes and acrylamide formation in fried potato slices. Food Research International, 38(1), 1-9.

Peleg, M. (1992). On the use of the WLF model in polymers and foods. Critical Reviews in Food Science and Nutrition, 32(1), 59-66.

Poncini, L. (1980). Thermal degradation of sucrose in solution-A review. The International Sugar Journal, 82(983), 332-335.

Poncini, L. (1981). Thermal degradation of sucrose in the crystalline phase and melt-A review. La Sucrerie Belge, 100, 221-228.

Rapusas, R. S., \& Driscoll, R. H. (1995). Kinetics of non-enzymatic browning in onion slices during isothermal heating. Journal of Food Engineering, 24(3), 417-429.

Richards, G. N. (1986). Initial steps in thermal degradation of sucrose. International Sugar Journal, 88(1052), 145-148.

Saguy, I., \& Karel, M. (1980). Modeling of quality deterioration during food processing and storage. Food Technology, 34(2), 78-85.

Saraiva, J., Oliveira, J. C., Hendrickx, M., Oliveira, F. A. R., \& Tobback, P. (1996). Analysis of the inactivation kinetics of freeze-dried $\alpha$ amylase from bacillus amyloliquefaciens at different moisture contents. Lebensmittel-Wissenschaft und-Technologie, 29(3), 260-266.

Schoebel, T., Tannenbaum, S. R., \& Labuza, T. P. (1969). Reaction at limited water concentration-1. Sucrose hydrolysis. Journal of Food Science, 34(4), 324-329.

Slade, L., \& Levine, H. (1991). Beyond water activity: recent advances based on an alternative approach to the assessment of food quality and safety. Critical Reviews in Food Science and Nutrition, 30(2,3), $115-360$.

van Boekel, M. A. J. S. (1996). Statistical aspects of kinetic modeling for food science problems. Journal of Food Science, 61(3), 447-485,489.

van Boekel, M. A. J. S. (2001). Kinetic aspects of the Maillard reaction: a critical review. Nahrung, 45(3), 150-159.

Vukov, K. (1965). Kinetic aspects of sucrose hydrolysis. The International Sugar Journal, 67, 172-175.

Zwietering, M. H., Jöngenburger, I., Rombouts, F. M., \& Riet, K. V. (1990). Modeling of the bacterial growth curve. Applied and Environmental Microbiology, 56(6), 1875-1881. 